科 学 通 报

\title{
离子通道抑制剂对大豆电位传递的影响 *
}

\author{
杨根平 ${ }^{(1)}$ 裴真明 荆家海 ${ }^{1}$ 汤章城 \\ (中国科学院上海植物生理研究所, 上海 200032; (1) 西北农业大学农学系, 陕西杨陵 712100)
}

\section{关键词电位传递、离子通道抑制剂、烧伤刺激、大豆}

植物体内存在刺激电位传递的现象已经得到广泛证明 ${ }^{[1]}$, 近来许多研究工作对电位在植 物体内可能的生理作用进行了探讨, 揭示了体内电信号传递的可能或潜在的生理意义 ${ }^{[1.2]}$. 国 内学者娄成后及其领导的实验室对高等植物体内电位的产生, 传递途经以及与物质运输的关 系做了较深人的研究 ${ }^{[23]}$. 然而, 关于高等植物体内长距离电信号传递的生物化学基础, 目前 还缺乏研究. 事实上, 植物动作电位机理的研究起始于 30 年代, 那时仅限于对轮藻细胞的观 察. 50 年代初, Hodgkin 和 Huxley 提出了动物神经细胞兴奋性传导的离子机理, 这一理论在 低等植物上也得到证明. 80 年代以来, 有关高等植物电位传递机理研究的报道逐步增多 ${ }^{[4,5]}$. 任海云等 ${ }^{[3]}$ 发现植物体内电波传递需要生活细胞的参与, Trebacz 等 ${ }^{[6}$ 在苔类植物上发现离子 通道抑制剂可以抑制动作电位的传递, 并证明动作电位的发生需要代谢过程的参与, 因此高 等植物体内电位传递可能类似于动物细胞以及低等单细胞或多细胞植物, 后者的膜电位传递 与膜上离子通道的活化有直接的关系, 近年来对植物离子通道研究的兴起, 给探索高等植物 电位传递机理提供了新的思路, $\mathrm{K}^{+}$通道和 $\mathrm{Ca}^{2+}$ 通道是植物体内最重要的离子通道 ${ }^{[7}$, 本工作 用这两个通道的抑制剂 ${ }^{\mathfrak{9}}$ 处理大豆植珠, 观察烧伤刺激诱导的电位传递规律, 以探讨电位传递 与质膜离子通道之间的可能关系, 发现 $\mathrm{LaCl}_{3}\left(\mathrm{Ca}^{2+}\right.$ 通道抑制剂 $)$ 和 $\mathrm{TEA}^{+}\left(\mathrm{K}^{+}\right.$通道抑制剂 $)$ 可明显抑制烧伤刺激的电位传递, 这一发现表明细胞质膜上的离子通道可能参与了高等植物 体内细胞内和细胞间电信号的传递, 外界刺激可能活化了细胞膜的离子通道, 引起质膜两侧 离子分布变化, 由此导致膜电位改变, 这一电信号可沿着共质体区细胞质膜以局部电流的方 式传递 ${ }^{[3]}$, 最终到达植物各个部分.

\section{1 材 料与 方 法}

\section{1 材料}

大豆 (东解选) 种子经 $\mathrm{HgCl}_{2}$ 消毒 $5 \mathrm{~min}$, 吸涨, 暗中萌发后移栽于人工气候室 (光强 350 $\mu \mathrm{mol} \cdot \mathrm{m}^{-2} \cdot \mathrm{s}^{-1}$, 温度 $25{ }^{\circ} \mathrm{C}$, 湿度 $70 \%$ ) 中生长, 至出现第一片三出复叶时, 移至实验室内 (自 然漫散光, $15-20^{\circ} \mathrm{C}$ ) 适应 $24 \mathrm{~h}$, 从茎基部剪下插人 $1 / 2$ 浓度 Hoagland 营养液中继续适应 $24 \mathrm{~h}$, 然后转人含有各种抑制剂的营养液中, 一定时间后测定烧伤刺激的电信号.

1994-01-21 收稿, 1994-04-16 收修改稿.

* 国家自然科学基金资助项目. 


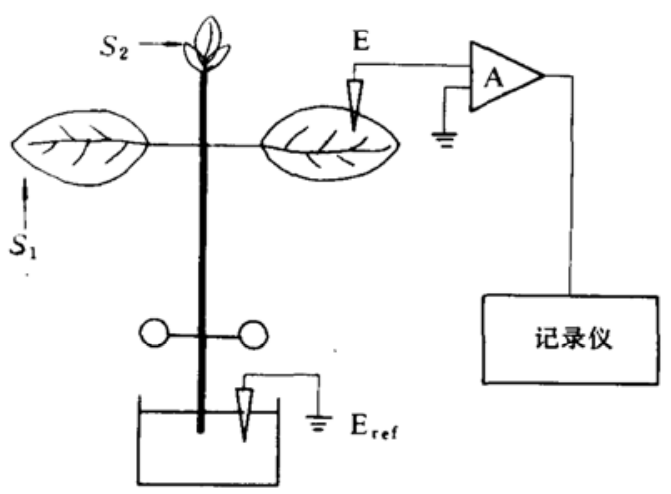

图 1 实验装置及材料处理部位示意图 $S_{1}$ 和 $S_{2}$ 为烧伤刺激位点, $\mathrm{E}$ 和 $\mathrm{E}_{\mathrm{rer}}$ 分别为测量电极和参考电极, A 为放大器

采用任海云介绍的方法 ${ }^{[3]}$, 用火焰顶部接触叶尖 $1-2 \mathrm{~s}$.

\section{2 实 验 结 果}

\section{$2.1 \mathrm{TEA}^{+}$和 $\mathrm{La}^{3+}$ 对叶片呼吸作用的影响}

$\mathrm{TEA}^{+}$和 $\mathrm{La}^{3+}$ 处理 $3 \mathrm{~h}$ 后用氧电极测定了叶片暗呼吸速率的变化, 结果见表 $1,0.1 \mathrm{mmol} / \mathrm{L}$ $\mathrm{TEA}^{+}$处理对呼吸无明显影响, 浓度提高, 对呼吸的抑制作用增大, $10 \mathrm{mmol} / \mathrm{L}$ 对呼吸的抑制 度达 $29 \%, \mathrm{La}^{3+}$ 对呼吸略有影响, $10 \mathrm{mg} / \mathrm{mL}$ 浓度的抑制率为 $12 \%$, 从外观看植物无可见变 化.

表 $1 \mathrm{TEA}^{+}$和 $\mathrm{La}^{3+}$ 对大豆叶片呼吸作用的影响

\begin{tabular}{cccc}
\hline 抑制剂 & 浓度 & 平均呼吸速率 $(\mu \mathrm{mol} / \mathrm{g} \cdot \mathrm{h})$ & 呼吸抑制率 $($ 占对照 \%) \\
\hline 对照 & & 16.52 & 0 \\
$\mathrm{TEA}^{+}$ & $0.1 \mathrm{mmol} / \mathrm{L}$ & 15.26 & 7.6 \\
& $10 \mathrm{mmol} / \mathrm{L}$ & 11.67 & 29.4 \\
& $20 \mathrm{mmol} / \mathrm{L}$ & 11.51 & 30.3 \\
$\mathrm{La}^{3+}$ & $10 \mathrm{mg} / \mathrm{mL}$ & 14.41 & 12.8 \\
& $20 \mathrm{mg} / \mathrm{mL}$ & 13.37 & 19.1 \\
\hline
\end{tabular}

\section{2 大豆体内烧伤刺激诱导的电位传递}

对大豆真叶进行烧伤刺激, 可很快在另一真叶上检测到电位信号的变化, 整个波形 (图 2) 与 Roblin 等 ${ }^{(8)}$ 在 Vicia faba 中观察到的电位波形极其相似. 同时, 也观察到另一类波峰, 主 要是动作电位结束后很快升到零点 (或平衡点) 以上, 即向正向偏移, 然后再出现较大的变异 电位, 如图 2b 所示.

\section{$2.3 \mathrm{TEA}^{+}$对大豆刺擞电位传递的抑制作用}

根据 $\mathrm{TEA}^{+}$对呼吸速率的影响, 选用 $0.1 \mathrm{mmol}^{\mathrm{TEA}}{ }^{+}$处理大豆植株, 测定 $(n=54)$ 烧伤刺 激的电信号传递, 发现 TEA ${ }^{+}$经去根苗吸收 $(3 \mathrm{~h})$, 可部分或全部抑制电位传递 (图 3), 图 3 是 $0.1 \mathrm{mmol} / \mathrm{L} \mathrm{TEA}^{+}$处理的几种典型电位记录曲线, 它们的波形复杂无规律, 但明显与对照 (图 2)不同. $0.1 \mathrm{mmol} / \mathrm{L} \mathrm{TEA}^{+}$处理可使测定样品的 $33 \%$ 不出现动作电位, 即使有动作电位, 其 
峰值很小, 也不规则. 有时在动作电位之后出现迅速正向偏移, 远离零点, 并在 $30 \mathrm{~min}$ 内不能 回复. 总之, $\mathrm{TEA}^{+}$对电位传递的抑制效应是肯定的.

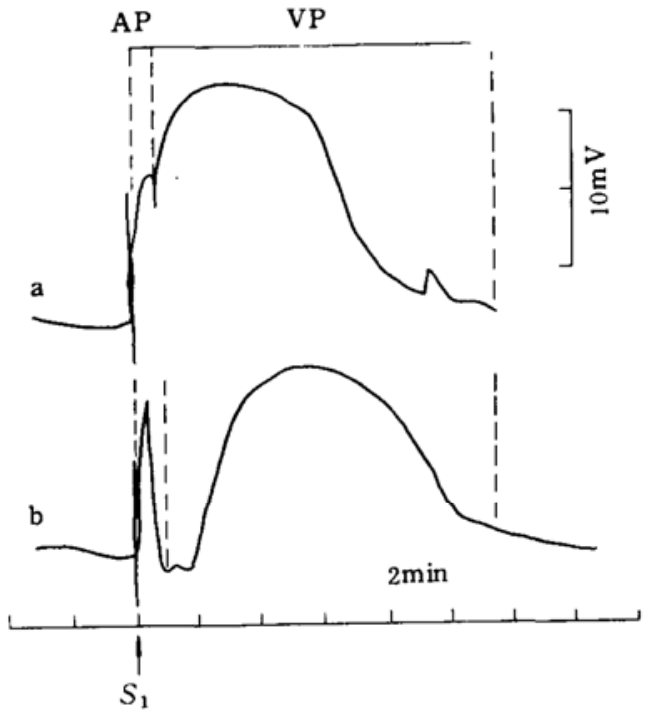

图 2 大豆植株烧伤刺激引起的电位及其传递 AP 为动作电位, VP 为变异电位, $S_{1}$ 指刺敞开始时间 及部位; $\mathrm{a}$ 和 $\mathrm{b}$ 为两类典型的电位波形

\section{$2.4 \mathrm{LaCl}_{3}$ 对刺湤电位传递的抑制}

图 4中分别对真叶 $\left(S_{1}\right)$ 和幼叶 $\left(S_{2}\right)$ 进行 烧伤刺激, 对照 $(\mathrm{CK})$ 出现两个明显的电位 峰 (图 2), $10 \mathrm{mg} / \mathrm{mL} \mathrm{LaCl}$ 处理, 完全抑制了 大豆植株的刺激电位传递, 重复率达 $90 \%$, $0.1-5 \mathrm{mg} / \mathrm{mL} \mathrm{LaCl}$ 对电位传递影响较小 (结 果未列出), $\mathrm{LaCl}_{3}$ 浓度低于 $1 \mathrm{mmol} / \mathrm{L}$ 时, 似乎 具有一定的刺激效应,使动作电位和变异电位 峰值提高, 并使其时间延长; 其次, 动作电位之 后电信号迅速正向偏移, 这与 $\mathrm{TEA}^{+}$处理类 似.

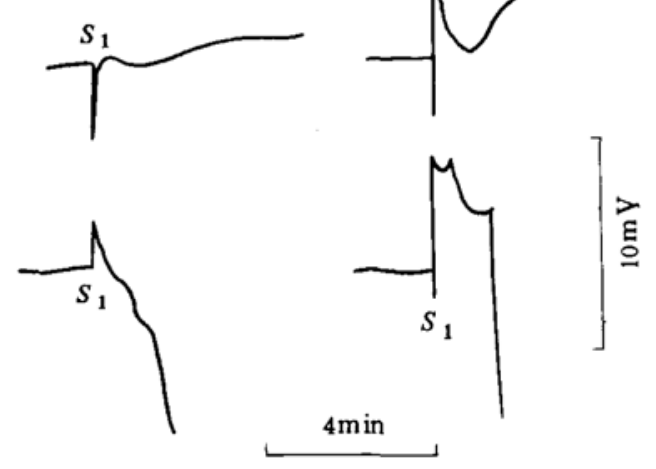

图 $3 \mathrm{~K}^{+}$通道抑制剂 $\mathrm{TEA}^{+}$处理对大豆植株电位传 递的影响

$\mathrm{TEA}^{+}$浓度为 $0.1 \mathrm{mmol} / \mathrm{L}, \dot{S}$ 指刺激开始时间及部位

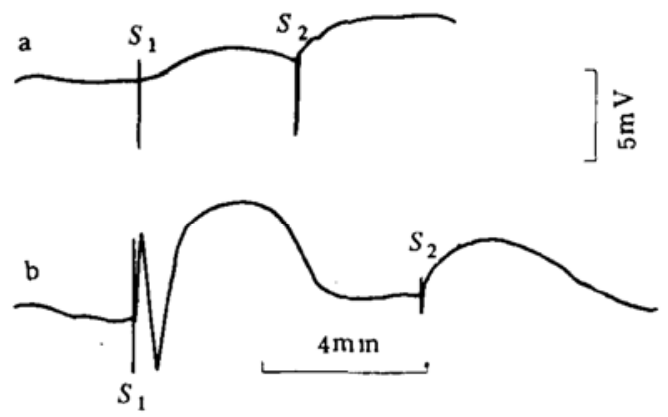

图 $4 \mathrm{Ca}^{2+}$ 通道抑制剂 $\mathrm{La}^{3+}$ 对电 位传递的影响 $S_{1}$ 和 $S_{2}$ 分别指两个部位刺政开始时间; $\mathrm{a}$ 和 b 分别为阻 断剂处理和对照

\section{3 讨 论}

大豆系非敏感性植物, 经烧伤刺激可以引起电位在体内传递. 其电位波形的典型特征是 快速而峰窄的动作电位之后跟随缓慢出现的变异电位, 后者有时不止一个峰出现. 细胞离子 通道的抑制剂处理, 可以阻断电位传递. $\mathrm{K}^{+}$通道的抑制剂 $\mathrm{TEA}^{+}$抑制电波传递的方式与 $\mathrm{Ca}^{2+}$ 通道抑制剂 $\mathrm{La}^{3+}$ 的作用方式似乎不同,前者的抑制率 (抑制次数占总测定次数的百分 数, $n=57$, 浓度由 $0.1 \mathrm{mmol} / \mathrm{L}$ 到 $30 \mathrm{mmol} / \mathrm{L}$ ) 较低, 随着浓度提高, 抑制率提高, 未被抑制的动 作电位峰值也降低; 而后者, 则在 $5.0 \mathrm{mg} / \mathrm{mL}$ 浓度以下几乎无抑制效应, $10.0 \mathrm{mg} / \mathrm{mL}$ 可完全抑 
制电信号传递, 表现出动作电位全有或无的明显特征. 植物 细胞质膜上 3 种主要离子 $\left(\mathrm{K}^{+}\right.$, $\mathrm{Ca}^{2+}$ 和 $\left.\mathrm{Cl}^{-}\right)$通道 ${ }^{[9]}$ 中, $\mathrm{Ca}^{2+}$ 通道最为重要, 它具有调节离子跨膜转运的作用 ${ }^{[6} . \mathrm{Ca}^{2+}$ 通过通道进 人细胞质后, 活化或刺激 $\mathrm{Cl}^{-}$和 $\mathrm{K}^{+}$通道, 引起 $\mathrm{Cl}^{-}$和 $\mathrm{K}^{+}$外流, 导致膜电位变化. 由此可解 释 $\mathrm{LaCl}_{3}$ 的抑制效应. 另外, $\mathrm{TEA}^{+}$处理引起电位正向偏移, 可能类似于动物及低等单或多细 胞植物上检测到的极化后电位 (after potentia) ${ }^{[10]}$. 低浓度的 $\mathrm{LaCl}_{3}$ 处理也发生电位正向偏 移. Boari 等 ${ }^{[10]}$ 研究烧伤刺激信号传递时, 在4种植物上记录到同样的现象. 当然本工作中 所使用的抑制剂广泛应用于动植物离子通道研究中, 其是否也影响体内其它生理生化过程还 未见报道. 本研究结果中所采用的抑制剂浓度对呼吸代谢影响不大, 但在相同浓度下 $\mathrm{La}^{3+}$ 和 $\mathrm{TEA}^{+}$对电位传递抑制效应却非常明显, 说明它们对电位传递的作用非常可能是直接的, 通过 抑制呼吸而对电位传递产生的影响可能不大. 动作电位和变异电位同时被抑制的事实表明二 者的传递都与细胞质膜有关. 我们推测, 整个电位的远距离传递可能经由植物体内的共质体 系统连续地进行 ${ }^{[2]}$, 其中细胞质膜担负着负载和传递电位的功能; 同时, 与动物神经细胞中相 似, 植物动作电位的产生和传递主要是细胞质膜电压依赖型离子通道作用的结果.

\section{参 考 文 献}

[1] Wildin, D. C., Thain, J. F., Minchin, P. E. F. et al., Nature, 1992, 360;62-65.

[2] 娄成后,植物生理学通讯, 1993, 29:81-83.

[ 3] 任海云、娄成后,植物生理学报, 1993, 29:265-274.

[4] Trebacz, K., Tarnecki, R., Zawadzki, T., Physiol. Plant, 1989, 75: 24-30.

[5] Davies, E., Plant Cell and Enviroment., 1987, 10:623-631.

[6] Shimmen, T., Tazawa, M., Plant Cell Physiol., 1983. 24: 1511-1524.

[ 7] Tester, M., New Phytol., 1990, 114: 305-340.

[8] Fromm, J., Spanswick, R., J. Exp. Bot., 1993, 44: 1119-1125.

[9] Eshrick, W., Fromm, J., Evert. R. F.. Bot. Actu. 1988, 101:327-331.

[10] Boari, F., Malone. M., J. Exp. Bot., 1993, 44: $741-746$. 